\title{
Prevalence of Type 2 (non-insulin-dependent) diabetes mellitus and impaired glucose tolerance in the Japanese general population: the Hisayama study
}

\author{
T. Ohmura, K. Ueda, Y. Kiyohara, I. Kato, H. Iwamoto, K. Nakayama, K. Nomiyama, S. Ohmori, T. Yoshitake, \\ A. Shinkawu, Y.Hasuo, M. Fujishima
}

The Second Department of Internal Medicine, Faculty of Medicine, Kyushu University, Fukuoka, Japan

\begin{abstract}
Summary. We determined the population-based prevalence of diabetes mellitus in members of the Japanese community, Hisayama aged $40-79$ years old by a $75-\mathrm{g}$ oral glucose tolerance test. The basic population used to calculate diabetic prevalence was 1,077 men $(72.8 \%$ of the whole population in the same age range) and 1,413 women (80.8\%) including ten diabetic patients on insulin therapy. In addition, we compared the prevalence of history of diabetes which was acquired by interview or questionnaire, between participants and non-participants in the 75-g oral glucose tolerance test, but they were not statistically different. The age-adjusted prevalence of diabetes to world population was $12.7 \%$ for
\end{abstract}

men and $8.4 \%$ for women, and that of impaired glucose tolerance was $19.6 \%$ for men and $18.4 \%$ for women. These figures were much higher than those previously reported from several Japanese communities. The results obtained from the present study could reveal true prevalence of diabetes among the Japanese population. In addition, the reasons for the increasing prevalence of diabetes among the recent Japanese population are also discussed.

Key words: Prevalence of diabetes mellitus, 75 -g oral glucose tolerance test, a Japanese community, population-based epidemiologic study, Hisayama.
Several studies have reported the prevalence of diabetes mellitus among the Japanese general population, which had been determined by oral glucose tolerance testing (OGTT) [1-6]. Although the criteria used to screen for diabetes was either the same or very similar to that of the World Health Organization (WHO) (1985) [7], the reported prevalence rates were less frequent compared to those from Japanese immigrants in the United States [6,8, 9] or east Asian-Pacific populations [10,11-13]. This may partly be due to the low rates of participation from the whole population (less than $15 \%$ ) or to the different screening methods utilized in the Japanese studies. In one study [4], for example, the 75-g OGTT was performed only on subjects who had glycosuria.

We attempted to estimate the true prevalence of diabetes among the Japanese general population using a 75-g OGTT for testing the majority of residents in the town of Hisayama, Kyushu, Japan. Furthermore, we compared the frequency of a diabetic history between the participants and non-participants to confirm that there was no skewed bias among the participating subjects.

\section{Subjects and methods}

The town of Hisayama and its inhabitants: Hisayama is a subrural town located approximately $33^{\circ}$ north and adjacent to the city of Fukuoka. It has a population of 1.16 million and is a large urban centre on Kyushu Island in the southern part of Japan. The population of the town is approximately 7,000 and this number of inhabitants has been stable for 30 years.

According to the 1985 census, the age distribution of the Hisayama population was almost identical to that of the whole of Japan, but the frequency of persons aged 65 years or over in Hisayama was slightly higher $(12.2 \%$ vs $10.3 \%$, respectively) $[14,15]$.

The occupations of the subjects were categorized into three types according to the census for labour and products in Japan. Of the employed population aged 40-79 years in the town, $14.6 \%$ were engaged in primary industry (agriculture, fishery, forestry), $29.8 \%$ in secondary industry (mining, construction, manufacture), and $55.6 \%$ in tertiary industry (commerce, restaurant, transport, communication, finance, insurance, supplier with electricity, gas or water, real estate business, service industry, unclassified official business) [16]. The frequency-distribution was very similar to that of all Japanese employees in the same age-range; $14.5 \%, 33.4 \%$ and $52.2 \%$, respectively [17].

A nutritional survey of Hisayama residents was conducted in 1985 [18]. The carbohydrate and fat energy ratio to the total energy intake were $0.56,0.25$, respectively. These were similar to the data from a 1989 National Nutritional Survey which was based on a random sample of approximately 20,000 subjects selected from 300 areas throughout Japan $(0.59,0.26$, respectively $)$ [19]. 
Residents in Hisayama, Fukuoka, 1988, aged $40-79$ years $(\mathrm{n}=3227)$

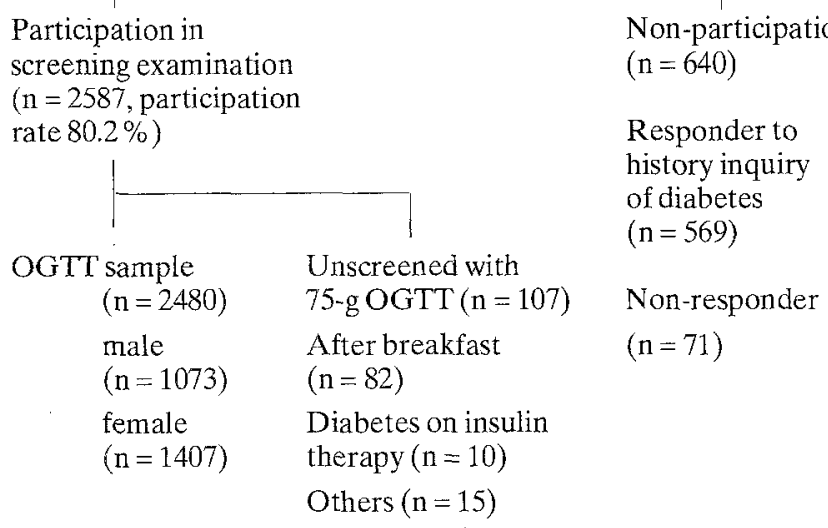

Fig. 1. Flow diagram of the study

Table 1. Participation of the subjects (\%) in a medical history interview and oral glucose tolerance test (OGTT)

\begin{tabular}{|c|c|c|c|c|c|c|}
\hline \multirow[t]{2}{*}{ Sex } & \multirow[t]{2}{*}{$\begin{array}{l}\text { Age } \\
\text { (years) }\end{array}$} & \multirow{2}{*}{$\begin{array}{l}\begin{array}{l}\text { Study } \\
\text { population }\end{array} \\
(n)\end{array}$} & \multicolumn{2}{|c|}{$\begin{array}{l}\text { Participation } \\
\text { in history inquiry }\end{array}$} & \multicolumn{2}{|c|}{$\begin{array}{l}\text { Participation } \\
\text { in OGTT }\end{array}$} \\
\hline & & & (n) & $(\%)$ & (n) & $(\%)$ \\
\hline \multirow[t]{2}{*}{ Male } & $\begin{array}{l}40-49 \\
50-59 \\
60-69 \\
70-79\end{array}$ & $\begin{array}{l}508 \\
444 \\
347 \\
180\end{array}$ & $\begin{array}{l}483 \\
436 \\
343 \\
179\end{array}$ & $\begin{array}{l}95.1 \\
98.2 \\
98.8 \\
99.4\end{array}$ & $\begin{array}{l}320 \\
329 \\
284 \\
144\end{array}$ & $\begin{array}{l}63.0 \\
74.1 \\
81.8 \\
80.0\end{array}$ \\
\hline & Total & 1479 & 1441 & 97.4 & 1077 & 72.8 \\
\hline \multirow[t]{2}{*}{ Female } & $\begin{array}{l}40-49 \\
50-59 \\
60-69 \\
70-79\end{array}$ & $\begin{array}{l}565 \\
513 \\
414 \\
256\end{array}$ & $\begin{array}{l}541 \\
506 \\
413 \\
255\end{array}$ & $\begin{array}{l}95.8 \\
98.6 \\
99.8 \\
99.6\end{array}$ & $\begin{array}{l}414 \\
428 \\
366 \\
205\end{array}$ & $\begin{array}{l}73.3 \\
83.4 \\
88.4 \\
80.1\end{array}$ \\
\hline & Total & 1748 & 1715 & 98.1 & 1413 & 80.8 \\
\hline
\end{tabular}

The Hisayama study: A prospective population survey has been conducted in the town of Hisayama since 1961 and is still ongoing. The initial aim of the study was to elucidate the true incidence of cerebral stroke and its risk factors among the general population of Japan [20], since cerebrovascular disease was the leading cause of death for the Japanese at that time. The design of the study is fundamentally that of a cohort study, and a prospective follow-up was focussed on subjects aged 40 or over, beyond which the frequency of cardiovascular diseases is expected either stepwise or abruptly to increase. A maximum effort was made in order to include more than $80 \%$ or $90 \%$ of the residents aged 40 or over in the cohort population. We have now established two study cohorts aged 40 or over in 1961 and 1974 [21], respectively, and each has been followed-up since then in the same manner. Any newly occurring cardiovascular diseases including cerebral stroke among the cohort population, were scrutinized based on clinical information including a neurovascular examination by the study team, as well as cranial computed tomography or other diagnostic methods. When a subject died, the cause(s) of death was verified by autopsy at the Department of Pathology, Kyushu University and detailed pathologic findings have been accumulated. The total autopsy rate throughout the follow-up reached $82,4 \%$. Physical or biomedical characteristics for the residents including blood pressure, anthropometric measures, urinalysis, electrocardiogram, serum cholesterol etc. were determined by the cross-sectional examinations carried out either every 2 or 5 years, and their relationship to the occurrence of cardiovascular diseases was studied. Several reports have already described the incidence of cerebral stroke and coronary heart disease and their characteristics, risk factors for cardiovascular disease and its changing pattern during the long-term follow-up [21-24]. Prevalence studies on diabetes mellitus have already been conducted in 1961 and in 1973-1974 [25], however, the design and methods of these studies were not completely satisfactory. We have also observed that impaired glucose tolerance is an independent and strong risk factor for cerebral infarction [26]. Thus, a new and more extensive study on the prevalence of diabetes among the Hisayama population was justified.

The present study: We studied the prevalence of diabetes at a regular, cross-sectional examination during the period between 29 June 1988 and 14 November 1988. Using the town registry, 82 individuals were excluded, who had been under long-term medical care for various chronic diseases. Thus, a total of 3,227 residents aged 40-79 years old of both sexes comprised the baseline study population (Fig.1). Of these, 2,587 subjects $(80.2 \%)$ consented to participate in the study.

The screening examination included an interview at which inquiries were made about diabetes, hypertension, stroke, ischaemic heart disease and other chronic diseases previously diagnosed by physicians and also about any drugs including insulin and oral hypoglycaemic agents that had been previously prescribed. Questions on personal drinking and smoking habits were also asked. At the interviews, participants who were fasting could undergo the OGTT, but 82 subjects were excluded, since they had already eaten breakfast. Four men and six women were on insulin therapy for Type 2 (non-insulin dependent) diabetes, which had been diagnosed by their attendant physicians. We could not complete the OGTT in 15 subjects due to complaints of nausea or general fatigue during the ingestion of glucose. Subjects receiving oral hypoglycaemic agents omitted their medication until after the OGTT. Altogether, the OGTT was completed by 1,073 men and 1,407 women.

The study subjects ingested glucose and other carbohydrate solutions equivalent to $75 \mathrm{~g}$ of anhydrate glucose (Trelan G, Shimizu Pharmaceutical, Shimizu, Japan) between 08.00 and 10.30 hours after at least a 12-h overnight fast. For determination of plasma glucose and total cholesterol, blood was drawn twice from an antecubital vein before and $120 \mathrm{~min}$ after ingestion of the glucose using vacutainer tubes with heparin, EDTA, and fluoridated natrium and tubes to which no drug was added. Blood specimens were then transferred immediately after venepuncture to the central study laboratory (JML Inc., Fukuoka, Japan) in ice-cooled containers, where the tubes were centrifuged, and serum or plasma was separated. Plasma glucose was determined by the glucose-oxidase method using a Glucoroder-MK2 (A \& T Inc., Tokyo, Japan).

Total cholesterol levels were determined enzymatically in a fasting blood sample using an autoanalyser (TBA-80S; Toshiba Inc, Tokyo, Japan).

Blood pressures were obtained three times using a mercury sphygmomanometer (standard size cuff) in a sitting position. The average of the values was recorded.

Subscapular and triceps skinfold thickness, height, and body weight were measured in the standing position. Using a Keys-Brosek skinfold caliper (Imoto Ikakikai Inc., Fukuoka, Japan), subscapular skinfold thickness was measured just below the inferior angle of the right scapula. Triceps skinfold thickness was determined in the midline of the posterior aspect of the right arm, over the triceps muscle, at a point midway between the acromial process of the scapula and inferior margin of the olecranon process of the ulna. Body mass index (BMI) was defined as weight $(\mathrm{kg})$ divided by the square of the height (m)

According to the criteria recommended by the WHO (1985) [7], the examined subjects were divided into three groups: diabetes mellitus, impaired glucose tolerance, and normal glucose tolerance. The inclusion into diabetes mellitus required fasting plasma glucose being equal to or greater than $7.8 \mathrm{mmol} /$ or 2 -h plasma glucose value equal to or greater than $11.1 \mathrm{mmol} / 1$. Subjects with fasting plasma glucose less than $7.8 \mathrm{mmol} / 1$ and 2 -h value between 7.8 and $11.1 \mathrm{mmol} / \mathrm{l}$ were categorized as having impaired glucose tolerance.

For the prevalence study, we included ten subjects who were receiving insulin in the analysis, resulting in a total of 1,077 men ( $72.8 \%$ of male population aged 40 or over) and 1,413 women $(80.8 \%)$ as the study subjects (Table 1 ). 
Table 2. Comparison of the frequencies of subjects with history of diabetes between participants and non-participants in the oral glucose tolerance test

\begin{tabular}{|c|c|c|c|c|c|c|c|}
\hline \multirow[t]{2}{*}{ Sex } & \multirow{2}{*}{$\begin{array}{l}\text { Age } \\
\text { (years) }\end{array}$} & \multicolumn{3}{|c|}{ Participants } & \multicolumn{3}{|c|}{ Non-participants } \\
\hline & & $\begin{array}{l}\text { Subjects } \\
(n)\end{array}$ & $\begin{array}{l}\text { Cases } \\
(n)\end{array}$ & $(\%)$ & $\begin{array}{l}\text { Subjects } \\
(n)\end{array}$ & $\begin{array}{l}\text { Cases } \\
(n)\end{array}$ & $(\%)$ \\
\hline \multirow[t]{5}{*}{ Male } & $40-49$ & 320 & 18 & 5.6 & 163 & 8 & 4.9 \\
\hline & $50-59$ & 329 & 43 & 13.1 & 107 & 13 & 12.1 \\
\hline & $60-69$ & 284 & 37 & 13.0 & 59 & 9 & 15.3 \\
\hline & $70-79$ & 144 & 17 & 11.8 & 35 & 6 & 17.1 \\
\hline & Total & 1077 & 115 & 10.7 & 364 & 36 & 9.9 \\
\hline \multirow[t]{5}{*}{ Female } & $40-49$ & 414 & 10 & 2.4 & 127 & 3 & 2.4 \\
\hline & $50-59$ & 428 & 22 & 5.1 & 78 & 5 & 6.4 \\
\hline & $60-69$ & 366 & 40 & 10.9 & 47 & 5 & 10.6 \\
\hline & $70-79$ & 205 & 14 & 6.8 & 50 & 6 & 12.0 \\
\hline & Total & 1413 & 86 & 6.1 & 302 & 19 & 6.3 \\
\hline
\end{tabular}

Cases, Subjects with a positive history of diabetes

Table 3. Comparison of the data between participants in the present OGTT study and the National Nutritional Survey 1989

\begin{tabular}{|c|c|c|c|c|}
\hline & \multicolumn{2}{|l|}{ Male } & \multicolumn{2}{|l|}{ Female } \\
\hline & $\begin{array}{l}\text { Partici- } \\
\text { pants } \\
\text { in OGTT }\end{array}$ & $\begin{array}{l}\text { National }^{\mathrm{a}} \\
\text { Survey }\end{array}$ & $\begin{array}{l}\text { Partici- } \\
\text { pants } \\
\text { in OGTT }\end{array}$ & $\begin{array}{l}\text { National }{ }^{a} \\
\text { Survey }\end{array}$ \\
\hline & (mean) & (mean) & (mean) & (mean) \\
\hline $\begin{array}{l}\text { Skinfold thickness } \\
(\mathrm{mm})\end{array}$ & 23 & 28 & 37 & 39 \\
\hline $\begin{array}{l}\text { Total cholesterol } \\
(\mathrm{mmol} / \mathrm{l})\end{array}$ & 5.12 & 5.20 & 5.56 & 5.48 \\
\hline & $(\%)$ & $(\%)$ & $(\%)$ & $(\%)$ \\
\hline Hypertension $^{c}$ & 16.9 & 21.3 & 11.1 & 14.5 \\
\hline Habit of drinking & 62.1 & 53.9 & 9.1 & 6.2 \\
\hline Habit of smoking & 50.2 & 51.9 & 6.7 & 8.8 \\
\hline
\end{tabular}

${ }^{a}$ Age adjusted to the participants in the OGTT study.

${ }^{\mathrm{b}}$ Sum of triceps skinfold thickness and subscapular one.

' Systolic blood pressure $\geq 160 \mathrm{~mm} \mathrm{Hg}$ and/or diastolic blood pressure $\geq 95 \mathrm{~mm} \mathrm{Hg}$.

OGTT, Oral glucose tolerance test

Since the participation rates in younger age groups were relatively low $(<80 \%)$ compared with those in the older age groups, the medical histories (especially previous diagnoses of diabetes) of the non-attenders were obtained by either mail or telephone to certify that the study subjects did not deviate from the whole population. Of the 640 non-attenders, 569 subjects $(88.9 \%)$ provided information regarding their history of previously diagnosed diabetes by physicians and reasons for non-attendance (Fig.1). Therefore, we could collect information on whether he or she had previous diagnosis of diabetes out of a grand total of 1,441 men $(97.4 \%$ of the male residents) and 1,715 women (98.1\%) including both the attenders and non-attenders (Table 1).

The main reason that non-attenders would not participate in the OGTT examination was most often prior health screening by their family doctor or at places of employment. In addition, some subjects refused to undergo the examination because of a lack of free time due to their work schedule.

\section{Statistical analysis}

The SAS computer package (SAS Institute, Cary, NC, USA) was used to perform the two-tailed Student's $t$-test and chi-square test [27] for statistic calculations. A box-and-whisker plot was also generated using the SPLOT procedure in this computer package [28].
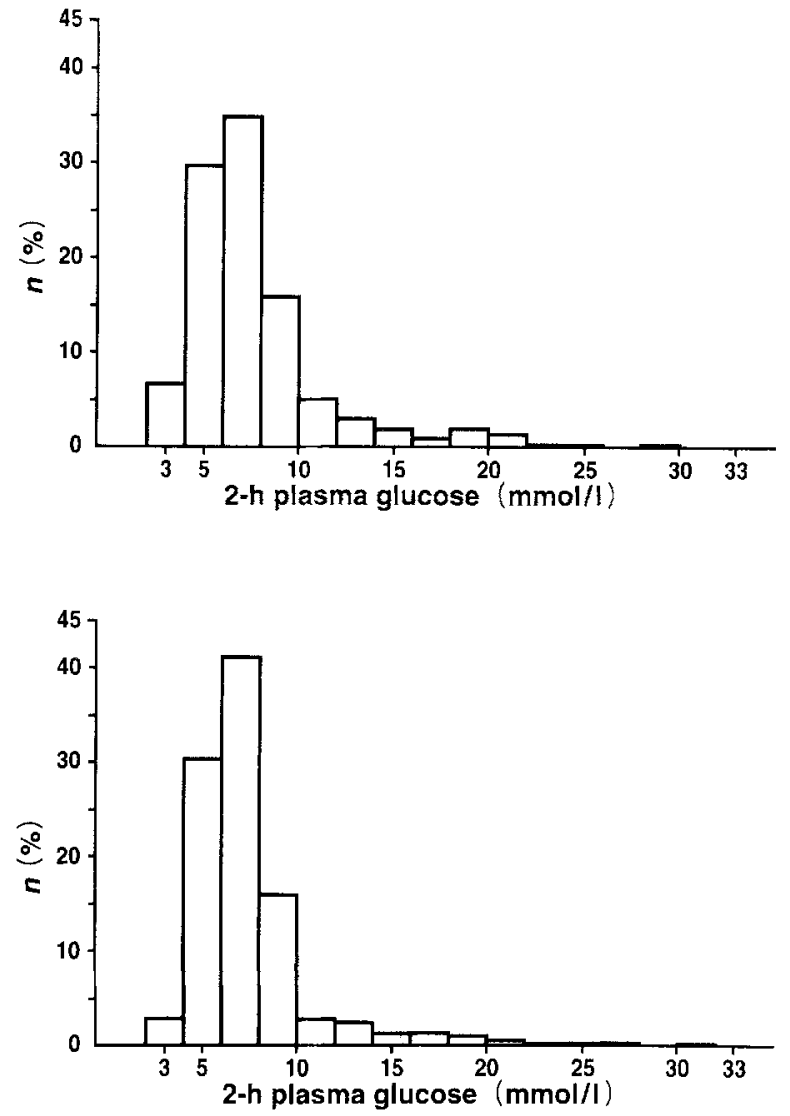

Fig. 2. Frequency distributions of $2-\mathrm{h}$ post-load glucose levels in $\mathrm{Hi}-$ sayama residents aged 40-79 years old. Upper panel, male subjects; lower panel, female subjects

\section{Results}

We compared the frequency of the subjects who had a previous history of diabetes between the non-participants and participants in the OGTT (Table 2). There was a higher frequency of diabetes history for the non-participants in the distribution of men aged 60-79 and women aged 70-79 than for the participants, but the difference was not significant in any age or sex group $(p>0.05)$.

To confirm that the subjects participating in the OGTT were similar to the general population, we compared the characteristics of the participants with those of the subjects from the National Nutritional Survey 1989 , who had been randomly selected throughout Japan [19] (Table 3). The skinfold thickness and the frequency of hypertension for our study subjects were lower than those in the National Survey, while the frequency of alcohol consumption was higher. However, the differences were not large. The BMI of our study subjects was $22.9 \mathrm{~kg} / \mathrm{m}^{2}$ for men and $23.0 \mathrm{~kg} / \mathrm{m}^{2}$ for women. These were similar to the data estimated from the mean values of height and weight of subjects aged 20 or over in the National Nutritional Survey; $22.8 \mathrm{~kg} / \mathrm{m}^{2}, 22.5 \mathrm{~kg} / \mathrm{m}^{2}$, respectively.

Figure 2 presents the frequency distribution of $2-\mathrm{h}$ post-load glucose values. The distribution was unimodal and skewed toward the upper glucose levels. The distribution in male subjects revealed a small peak around $20 \mathrm{mmol} / \mathrm{l}$ of 2 -h plasma glucose, but this did not necessarily represent a bimodal pattern. 


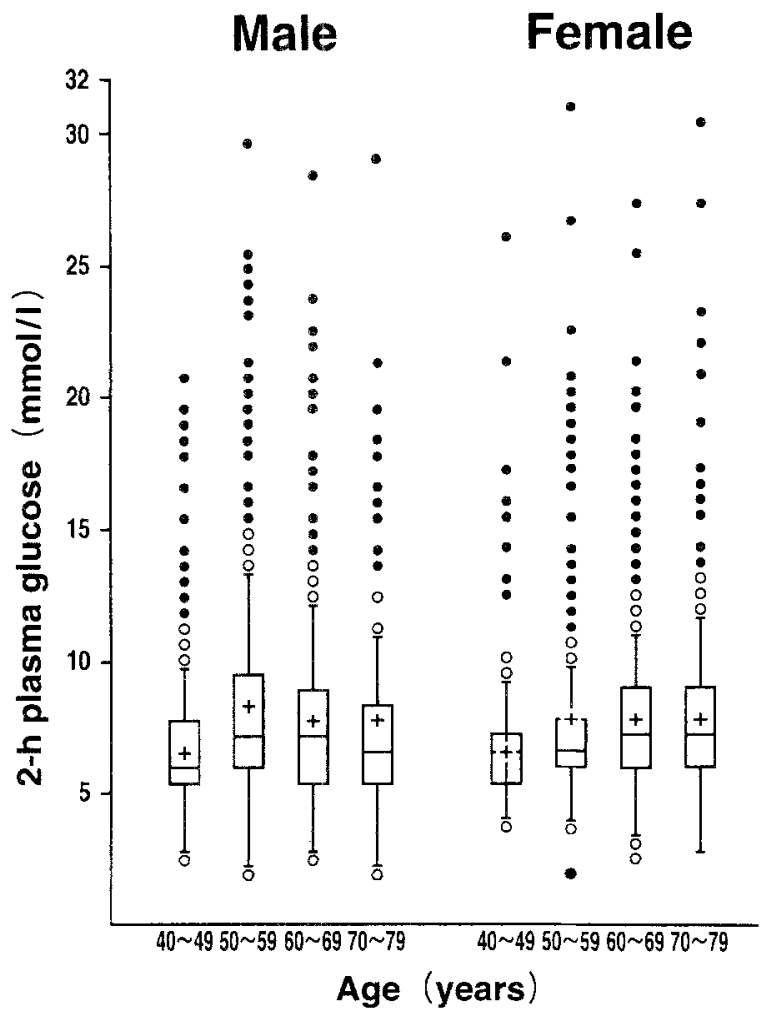

Fig. 3. Distribution of 2-h plasma glucose, Box-whisker plot: The bottom and top edges of the box are located at the sample 25th and 75 th percentiles. The center horizontal line is drawn at the sample median and plus sign is at the sample mean. The central vertical line extended from the box as far as the data extend to a distance of, at most, 1.0 interquartile ranges. The interquartile range is the distance between the 25 th and the 75 th sample percentiles. Any value more extreme than this is marked with an open circle if it is within the 1.5 interquartile ranges of the box, or with a solid circle if it is still more extreme
Figure 3 is a box-and-whisker plot of 2-h-plasma glucose by sex and age-decades, presenting the values of the mean, median, 25th and 75th percentile and extremely deviated values. The same skewed distribution in every age-decade for both sexes was observed.

Table 4 shows the prevalence of diabetes and impaired glucose tolerance by sex and age groups. Among persons under 60 years of age, the prevalence of diabetes for men was higher than that for women $(p<0.05)$; in particular, the prevalence for men aged $50-59$ was $19.5 \%$, which was the highest among all age and sex groups. There was no statistical difference after the age of 60 between men and women $(p>0.05)$. After the age groups were adjusted to world standard population [29], the overall prevalence of diabetes was $12.7 \%$ for men, and $8.4 \%$ for women. The prevalence of impaired glucose tolerance for male subjects aged 60-69 was $27.5 \%$, which was the highest among all male groups, while that for women increased with advanced age-decades. There was no significant difference in the prevalence of impaired glucose tolerance between men and women in any age group $(p>0.05)$. The overall age-adjusted prevalence was $19.6 \%$ for men and $18.4 \%$ for women.

\section{Discussion}

Table 5 summarizes the prevalence rates of diabetes previously reported from Japanese communities and Japanese immigrants to United States. The age-adjusted prevalence of diabetes among residents of Hisayama in the present study was $12.7 \%$ for men and $8.4 \%$ for women, which was much higher than those reported from other community studies in Japan [1-6] except for women in the study conducted in Hiroshima [6].

Table 4. Prevalence of diabetes and impaired glucose tolerance in participants in OGTT

\begin{tabular}{|c|c|c|c|c|c|c|c|}
\hline \multirow{2}{*}{$\begin{array}{l}\text { Age } \\
\text { (years) }\end{array}$} & \multicolumn{3}{|l|}{ Male } & \multicolumn{3}{|l|}{ Female } & \multirow{2}{*}{$\begin{array}{l}\text { Male/Female } \\
\text { ratio }\end{array}$} \\
\hline & $\begin{array}{l}\text { Subjects } \\
(n)\end{array}$ & $\begin{array}{l}\text { Cases } \\
(n)\end{array}$ & $(\%)$ & $\begin{array}{l}\text { Subjects } \\
(n)\end{array}$ & $\begin{array}{l}\text { Cases } \\
(n)\end{array}$ & $(\%)$ & \\
\hline$\overline{\text { Diabete }}$ & & & & & & & \\
\hline $40-49$ & 320 & 24 & $7.5^{\mathrm{a}}$ & 414 & 16 & 3.9 & 1.9 \\
\hline $50-59$ & 329 & 64 & $19.5^{\mathrm{a}}$ & 428 & 39 & 9.1 & 2.1 \\
\hline $60-69$ & 284 & 37 & 13.0 & 366 & 50 & 13.7 & 0.9 \\
\hline $70-79$ & 144 & 18 & 12.5 & 205 & 24 & 11.7 & 1.1 \\
\hline \multicolumn{3}{|c|}{ Age-adjusted ${ }^{c}$} & $\begin{array}{l}12.7 \\
(10.7-14.7)^{b}\end{array}$ & & & $\begin{array}{l}8.4 \\
(7.0-9.8)^{b}\end{array}$ & \\
\hline \multicolumn{8}{|c|}{ Impaired glucose tolerance } \\
\hline $40-49$ & 320 & 49 & 15.3 & 414 & 58 & 14.0 & 1.1 \\
\hline $50-59$ & 329 & 61 & 18.5 & 428 & 78 & 18.2 & 1.0 \\
\hline \multicolumn{3}{|c|}{ Age-adjusted } & $\begin{array}{l}19.6 \\
(17.2-22.0)^{b}\end{array}$ & & & $\begin{array}{l}18.4 \\
(16.4 \cdot 20.4)^{b}\end{array}$ & \\
\hline
\end{tabular}


Table 5. Prevalence rates for diabetes from surveys in Japan and of Japanese immigrants to the United States

\begin{tabular}{|c|c|c|c|c|c|c|c|}
\hline \multirow[t]{2}{*}{ Authors [Reference] } & \multirow[t]{2}{*}{ Year } & \multirow[t]{2}{*}{ Region } & \multirow[t]{2}{*}{ Country } & \multirow{2}{*}{$\begin{array}{l}\text { Age of subjects } \\
\text { at survey }\end{array}$} & \multicolumn{3}{|c|}{ Prevalence } \\
\hline & & & & & $\begin{array}{l}\text { Males } \\
(\%)\end{array}$ & $\begin{array}{l}\text { Females } \\
(\%)\end{array}$ & $\begin{array}{l}\text { Total } \\
(\%)\end{array}$ \\
\hline Kitazawa et al. [1] & $1981-1982$ & Tokyo & Japan & $30+$ & 4.0 & 2.2 & 3.6 \\
\hline Takashina et al. [2] & 1981-1982 & $\begin{array}{l}6 \text { rural } \\
\text { areas }\end{array}$ & Japan & $40-69$ & 4.4 & 3.8 & 3.9 \\
\hline Nakamura et al. [3] & 1982 & $\begin{array}{l}\text { Kumamoto } \\
\text { prefecture }\end{array}$ & Japan & $\begin{array}{l}50.9 \\
\text { (mean age) }\end{array}$ & & & 3.8 \\
\hline Baba et al. [5] & $1960-1.975$ & $\begin{array}{l}\text { Kasai } \\
\text { city }\end{array}$ & Japan & all ages & & & $0.98-1.64$ \\
\hline Hara et al. [6] & $1978-1980$ & $\begin{array}{l}\text { Hiroshima } \\
\text { prefecture }\end{array}$ & Japan & $40-96$ & 5.3 & 8.7 & 7.2 \\
\hline Fujimoto et al. [9] & $1983-1988$ & $\begin{array}{l}\text { King } \\
\text { County }\end{array}$ & USA & $45-74$ & & 16.1 & \\
\hline Present study & 1988 & Hisayama & Japan & $40-79$ & 12.7 & 8.4 & 10.2 \\
\hline
\end{tabular}

${ }^{a}$ Reported year

To ascertain that the difference was not derived from a bias of participation, we compared the frequencies of selfdeclared diabetes between the participants in OGTT and non-participants. In the present study, the prevalence of self-reported diabetes in participants in OGTT was not significantly different from that in non-participants in all age groups. One flaw in our study may be that while elderly subjects with a history of diabetes participated less in the OGTT examination, there was a higher frequency of self-reported diabetes for elderly non-participants in the OGTT. However, the number of non-participants was not large even for the elderly population, and therefore, the data on the total diabetic prevalence obtained here could not have been affected by this bias. Since an awareness of diabetes itself makes individuals hesitant to participate in a mass-screening for diabetes, previous studies conducted in Japanese communities may have underestimated the real diabetic-prevalence if the number of non-attenders was large. Therefore, the prevalence obtained here is representative of a near true frequency of diabetes or impaired glucose tolerance among the Japanese general population.

Whether self-reported data are useful for determination of the diabetic prevalence in the community remains controversial. The self-reported data concerning diabetes in the general population of the United States have been suggested only to reflect approximately $50 \%$ of the real prevalence [30]. In the present study, the crude prevalence of diabetes determined by OGTT was $13.3 \%$ for men and $9.1 \%$ for women, while that of self-reported diabetes in participants in OGTT was $10.7 \%$ for men and $6.1 \%$ for women. The difference between the OGTT and the selfreported data in the OGTT examined group was small. However, among the subjects with self-reported diabetes in the OGTT examined group, the frequency of the diabetic subjects certified by OGTT was only $62.6 \%$ for men and $76.7 \%$ for women. Thus, the rate of the pre- viously known diabetes among diabetic subjects diagnosed by the OGTT were $50.4 \%$ for men and $51.2 \%$ for women (data not shown).

Another point to be discussed is whether the increase in diabetic patients among the Japanese population is due to a more westernized lifestyle which includes being more sedentary and having a higher fat intake. An extremely high prevalence of diabetes was reported among the Japanese population who had immigrated to Los Angeles, Honolulu [6] and King County (USA) [8, 9]. Thus, immigration to the United States could be a risk factor for developing diabetes.

Data from the National Nutritional Survey in Japan indicate that the energy intake from fat has been increasing and that from carbohydrate has been decreasing since 1975 [19]. In the Hisayama study, the frequency of hypercholesterolaemia $(>6.20 \mathrm{mmol} / \mathrm{l})$ was very low in 1961 , being $1.8 \%$ for men and $3.3 \%$ for women, however, it increased gradually and reached a level of $15.4 \%$ for men, and $24.9 \%$ for women in 1988 . A similar pattern was observed in the prevalence of obesity [24]. Thus, diabetes prevalence would be expected to increase among the Japanese population under these conditions.

Sex difference of the prevalence of diabetes was observed in subjects aged 40-59 years. The Paris Prospective Study [31] suggested that diabetes diagnosed by the OGTT in the working male population may partially be a consequence of excessive alcohol consumption. The frequency of the men who drank regularly was much higher than that of women among the Hisayama residents. In particular, nearly $70 \%$ of the subjects consumed alcohol daily among the male residents aged 40-59. This might partially account for the sex difference in the prevalence of diabetes in the young age group. However, further study is needed to elucidate other risk factors associated with diabetes in the Japanese population, such as obesity, lipid metabolism, and insulin resistance. 
Distributions in frequency of the 2-h glucose values revealed a bimodal pattern in the Pima Indians and Nauruans indicating a tremendously high prevalence of diabetes $[32,33]$. The distribution pattern for those in the Hisayama population was continuous and unimodal in both sexes. There was no clear point of discrimination between the normal subjects and diabetic patients. Managing patients with impaired glucose tolerance among the Japanese population is important and should be introduced by a prospective follow-up study.

Acknowledgements. This study was supported in part by Grant-inAid for Diabetes Epidemiology Research, The Ministry of Health and Welfare, Japan, and Funds for Research of Metabolic Disorders (Takeda), and was also facilitated by the Japan-U.S. Cooperative Agreement in the Cardiovascular Disease Center in Osaka, and the National Institutes of Health, Blood and Lung in Bethesda, Maryland, USA.

\section{References}

1. Kitazawa Y, Murakami K, Goto Y, Hamazaki S (1983) Prevalence of diabetes mellitus detected by $75 \mathrm{~g}$ GTT in Tokyo. Tohoku J Exp Med 141 [Suppl]: 229-234

2. Takashina S, Tomaru H, Komatsu K et al. (1983) Prevalence of diabetes mellitus in a rural area of Japan by $75 \mathrm{~g}$ OGTT. Tohoku J Exp Med 141 [Suppl]: 235-241

3. Nakamura N, Ichinose K, Fukushima H, Uzawa H (1983) Studies on $75 \mathrm{~g}$ oral glucose tolerance in the inhabitants of Kumamoto prefecture, Japan. Tohoku J Exp Med 141 [Suppl]: 243-250

4. Shigeta Y, Kikkawa R, Kobayashi N, Katabami J (1983) A community study of diabetes in a population with a high diabetes mortality rate. Tohoku J Exp Med 141 [Suppl]: 257-260

5. Baba S, Ebara S, Kawaguchi A et al. (1976) A fifteen-year follow-up on diabetes in a Japanese rural district. Kobe J Med Sci 22: 197-209

6. Hara H, Kawase T, Yamakido M, Nishimoto Y (1982) Comparative observation of micro- and macroangiopathies in Japanese diabetics in Japan and U.S. A.. In: Abe H, Hoshi M (eds) Diabetic microangiopathy. Japan medical research foundation publication No.20. University of Tokyo Press, Tokyo, pp 377-391

7. WHO study group on diabetes mellitus (1985) Diabetes mellitus, report of a WHO study group. World Health Organization (technical report series 727), Geneva

8. Fujimoto WY, Leonetti DL, Kinyoun JL et al. (1987) Prevalence of diabetes mellitus and impaired glucose tolerance among second-generation Japanese-American men. Diabetes 36: 721-729

9. Fujimoto WY, Leonetti DL, Bergstrom RW, Kinyoun JL, Stolov WC, Wahl PW (1991) Glucose intolerance and diabetic complications among Japanese-American women. Diabetes Res Clin Prac 13: 119-130

10. Taylor R, Ram P, Zimmet P, Raper LR, Ringrose H (1984) Physical activity and prevalence of diabetes in Melanesian and Indian men in Fiji. Diabetologia 27: 578-582

11. Østbye T, Welby TJ, Prior IAM, Salmond CE, Stokes YM (1989) Type 2 (non-insulin-dependent) diabetes mellitus, migration and westernization: the Tokelau Island migrant study. Diabetologia 32: 585-590

12. King H, Taylor R, Zimmet P, Pargeter K, Raper LR, Beriki T, Tekanene $J$ (1984) Non-insulin-dependent diabetes (NIDDM) in a newly independent Pacific nation: the republic of Kiribati. Diabetes Care 7: 409-415

13. Waspadji S, Ranakusuma AB, Suyono $S$, Supartondo S, Sukaton U (1983) Diabetes mellitus in an urban population in Jakarta, Indonesia. Tohoku J Exp Med 141 [Suppl]: 219-228

14. Statistics bureau, management and coordination agency (1986) Results of the first basic complete tabulation, part 2, 40 Fukuoka-Ken. 1985 population census of Japan vol.2. Statistics bureau, management and coordination agency, Tokyo, pp 40-41
15. Statistics bureau, management and coordination agency (1986) Results of the first basic complete tabulation, part 1, Japan. 1985 population census of Japan vol. 2. Statistics bureau, management and coordination agency, Tokyo, pp 2-3

16. Statistics bureau, management and coordination agency (1987) Results of the second basic complete tabulation, part 2, 40 Fukuoka-Ken.1985 population census of Japan vol. 3. Statistics bureau, management and coordination agency, Tokyo, pp 202-203

17. Statistics bureau, management and coordination agency (1987) Results of the third basic complete tabulation, part 1, Japan. 1985 population census of Japan vol. 4. Statistics bureau, management and coordination agency, Tokyo, pp 132-135

18. Shirota T, Yoshizumi E (1990) Accuracy of nutritional survey using the simple method. Jap J Public Health 37: 100-108 (in Japanese)

19. Ministry of Health and Welfare (1991) Present status of national nutrition, the result of a national nutritional survey 1989. Daiichishuppan, Tokyo

20. Katsuki S (1966) Epidemiological and clinicopathological study on cerebrovascular disease in Japan. Prog Brain Res 21B: 64-89

21. Ueda K, Omae T (1985) Control of hypertension in a Japanese community. In: Bulpitt CJ (eds) Handbook of hypertension. Vol.6: Epidemiology of hypertension. Elsevier Science Publishers, Amsterdam, pp 412-423

22. Ueda K, Omae T, Hirota $Y$ et al. (1981) Decreasing trend in incidence and mortality from stroke in Hisayama residents, Japan. Stroke 12: 154-160

23. Ueda K, Hasuo Y, Kiyohara Y et al. (1988) Intracerebral hemorrhage in a Japanese community, Hisayama: incidence, changing pattern during long-term follow-up, and related factors. Stroke 19: 48-52

24. Fujishima M, Kiyohara Y, Ueda K et al. (1992) Smoking as cardiovascular risk factor in low cholesterol population: the Hisayama study. Clin Exp Hypertens [A] 14: 99-108

25. Ohmura T, Ueda K, Hasuo Y et al. (1990) Long-term prognosis of diabetics in the general population of Hisayama (1) Comparison of survival in subjects with and without glucose intolerance observed in two cohorts 13 years apart. J Jpn Diab Soc 33: 727-735

26. Ohmura T, Ueda K, Kiyohara Y et al. (1993) The impact of glucose intolerance on stroke incidence in a 22 -year follow-up study of the general population, the Hisayama study. J Japan Diab Soc 36: $17-24$

27. SAS Institute (1985) SAS user's guide, statistics, version 5 edn. SAS Institute, Cary, NC

28. Gerig TM (1986) the SPLOT procedure. In: Hastings RP (eds) SUGI Supplemental library user's guide. 5th edn. SAS Institute, Cary, NC, pp 531-534

29. Waterhouse J, Muir C, Shanmugartnam K, Powell J (eds) (1976) Cancer incidence in five continents, vol 3. International Agency for Research on Cancer, Lyon, p 456

30. Harris MI, Hadden WC, Knowler WC, Benett PH (1987) Prevalence of diabetes and impaired glucose tolerance and plasma glucose levels in U.S. population aged $20-74$ yr. Diabetes 36 : $523-534$

31. Balkau B, Eschwège E, Fontbonne A, Claude JR, Warnet JM (1992) Cardiovascular and alcohol-related deaths in abnormal glucose tolerant and diabetic subjects. Diabetologia 35: 39-44

32. Bennett PH, Burch TA, Miller M (1971) Diabetes mellitus in American (Pima) Indians. Lancet II: 125-128

33. Zimmet P, Whitehouse S (1978) Bimodality of fasting and twohour glucose tolerance distributions in a Micronesian population. Diabetes 27: 793-800

Received: 17 March 1993 and in revised form: 16 June 1993

Dr. T. Ohmura

Second Department of Internal Medicine

Faculty of Medicine

Kyushu University

Maidashi 3-1-1, Higashi-ku

Fukuoka City 812

Japan 